\title{
Microstructural Investigation of Glass Fiber Reinforced Polymer Bars
}

\author{
Omid Gooranorimi ${ }^{1 *}$, WimalSuaris ${ }^{1}$, Edward Dauer ${ }^{2}$, Antonio Nanni ${ }^{1}$ \\ ${ }^{1}$ Department of Civil, Architectural and Environmental Engineering, University of Miami, Coral Gables, 33146, \\ Florida, United States \\ ${ }^{2}$ Department of Biomedical Engineering, University of Miami, Coral Gables, 33146, Florida, United States \\ *Corresponding Author.Email: o.gooranorimi@umiami.edu, Phone: (+1) 7864499409
}

\section{Abstract}

Microstructural characteristics are crucialin understanding and predicting the behavior of glass fiber reinforced polymer (GFRP) bars used for concrete reinforcement. Considering the lack of extensive GFRP microstructuralknowledge, the main purpose of this study is to provide a documentation of GFRP microstructure and demonstrate its contribution in the durability of GFRP bars. Scanning electron microscopy (SEM) imaging was performed at different magnification levels on the cross-section of four different commercially available pristine GFRP bars. As a result of differences in the production method by pultrusion, each pristine bar presented a unique microstructural pattern including voids, defects, and fiber distribution.Two of the bars which demonstrated the most different patternswere exposed to accelerated conditioning inalkaline solution. The horizontal shear testwas performed and the results were compared with the pristine bars. The difference in microstructural patterns was found to significantly contribute to GFRP durability. These results can be used as a benchmark for the microstructure of commercially available pristine GFRP bars and serve as a base for monitoring possible changes after any conditioning or testing.

23 Keywords:A. Glass fibers, A. Polymer-matrix composites (PMCs), B. Microstructures, D. Electron 4 microscopy 


\section{Introduction}

26 Over the past two decades, glass fiber reinforced polymer (GFRP)bars have been demonstrated to be a

27 practical alternative for black, epoxy-coated and stainless steel rebars in reinforced concrete structures

28 (RC) especially in applications where durability and corrosion resistanceare required such as bridge decks

29 and marine structures.In addition, the use of GFRP is suitable for buildings that include equipment

30 sensitive to electromagnetic fields such as magnetic resonance imaging (MRI) units or bases for large

31 motors [1].

32 GFRP consistsof glass fibers as load carrying elements and resin which transfers and distributes the

33 loadamong the fibers. Microstructural patterns of the fibers and resin play a crucial role in understanding

34 the GFRP behavior. Different manufacturing parameters (such as pulling speed and dye temperature) lead

35 to variousGFRP microstructural patterns including the presence of voids and defects at various locations of GFRP cross-section. These patterns present combinations of continuousdefects and disconnected voids and lead to a unique pattern for each GFRP bar. Understanding the GFRP microstructural pattern may allow predicting the GFRP behavior under different loading conditions and states of stress.

Considering the lack of GFRP microstructural knowledge, the main purpose of this study is to provide a documentation of GFRP microstructure and investigate its possible contribution on GFRP durability.It is recognized that this study was limited to small sample size, a single bar diameter and four GFRP manufacturers; however, its findings are significant and provide a clear path for investigations to follow.

43 In the present study, four commercially available GFRP bars with a nominal diameter of $12.7 \mathrm{~mm}(0.5$ in.), equivalent to No. 4 steel rebar, were investigated. First, samples were properly polished and prepared for the microscopic examination. Next, scanning electron microscopy (SEM)was employed at different magnification levels to capture different aspects of the microstructural pattern includingi) existing defects and voids in the matrix; ii) fiber-matrix interface; and, iii) fiber distribution in the matrix.Panorama images of the entire cross-sectionswere provided to give a proper comparison between different bars. 
49 As part of this study, the possible effect of microstructural patterns on GFRP durability was

50 investigated[2][3][4]. Two types of the bar that demonstrated the most different microstructural patterns

51 were exposed to accelerated conditioning. The horizontal shear test was performed and the results were

52 compared with the pristine bars. Finally, SEM imaging was performed on conditioned bars to provide

53 additional evidence of the effect of the microstructural patterns on durability.

54

\section{2. GFRP Samples}

56 Four different GFRP barsall produced by pultrusion were selected in this study. Even Though, the

57 production process is nominally the same, different process parameters and bar constituents including

58 different surface characterestics have a profound effect on the result of the products.The selected GFRP

59 bars were: Ribbed deformed surface (GFRP-A), fine sand coated with helically wrapped fibers (GFRP-

60 B), double twisted fiber wrapped (GFRP-C) and coarse sand coated (GFRP-D). Table 1 provides the

61 nominal and measured cross-sectional areas for all GFRP bar types. The nominal area is based on a circle

62 with a nominal diameter of $12.7 \mathrm{~mm}$ (0.5 in.). The average measured area was computed based on a work

63 by Claure and coworkers [5]following a standard test method for density and specific gravity (relative

64 density) of plastics by displacement, ASTM D792[6].

65

66

67

68

69

70

71

72

73 
Table 1: GFRP nominal and measured cross-sectional areas

\section{Sample Preparation}

SeveralGFRPcoupons for each bar type were cut in anapproximate thickness of $7 \mathrm{~mm}$. The specimen surfaces were prepared by sanding using different grit levels (i.e., 180, 300, 600 and 1200) of sand paper and employing dedicated grinding and polishing equipment. Fine polishing completed the specimen preparation using a wet-polishing agent and polycrystalline diamond paste. Prior to imaging, specimens were placed in an oven at $60{ }^{\circ} \mathrm{C}$ for 24 hours to remove the moisture produced during polishing procedure. Samples were properly cleaned using an air-blower which also saved the SEM chamber from

91 being contaminated and provided higher quality images.A visual inspection of all coupons using a

92 magnifying lens confirmed that similar patterns existed and remained consistent for each bar type. Thus,

93 only three samples for each GFRP bar were randomly selected for further examination by SEM. Since

94 GFRP was a non-conductive material, an ion sputtering device was used to coat the samples with gold

95 prior to SEM examination.A photo of representative samples prior to microscopic examination is shown 96 in Figure 1. 


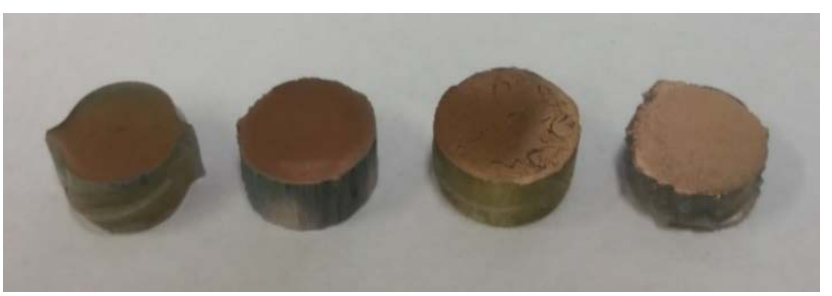

\section{SEM Imaging}

101 SEMwas conducted at low (0-200x), medium (200-1000x) and high (>1000x) magnification levels. Low 102 magnification images provided a general pattern of the cross-section by covering a higher area in each

103 image. This level was used to measure thelength of the existing defects. The images captured in this level 104 were stitched together to prepare the panorama image of the entire sections. Medium level magnification 105 imagesprovided a more detailed view of the section and eventually high-level magnification 106 imagingwasmainly conducted to monitor the single glass fibers. Three samples for each GFRP bar were 107 studied under SEM and since similar results were observed for the three, only representative images of 108 one of these samples for each GFRP bar is shown in this paper.

\section{5. Results and Discussions}

110 GFRP-Apresented a continuous defect at the edge (Figure 2). A large void with the length of 1.4 mmwas 111 observed at the center of the bar (Figure 3). The rest of cross-section did not show any voids or defects 112 and the resin properly impregnated the fibers (Figure 4). 

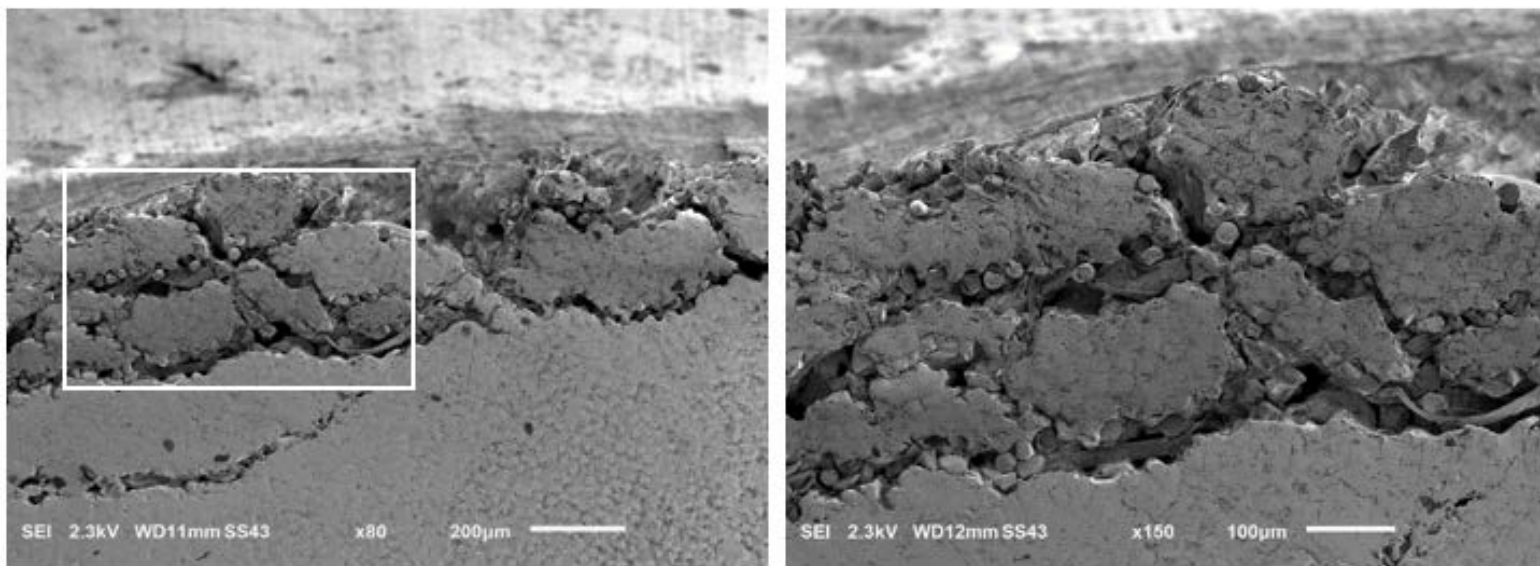

Figure 2:A defect at the edge of GFRP-A at magnification levels of 80x (left) and 150x (right)

115
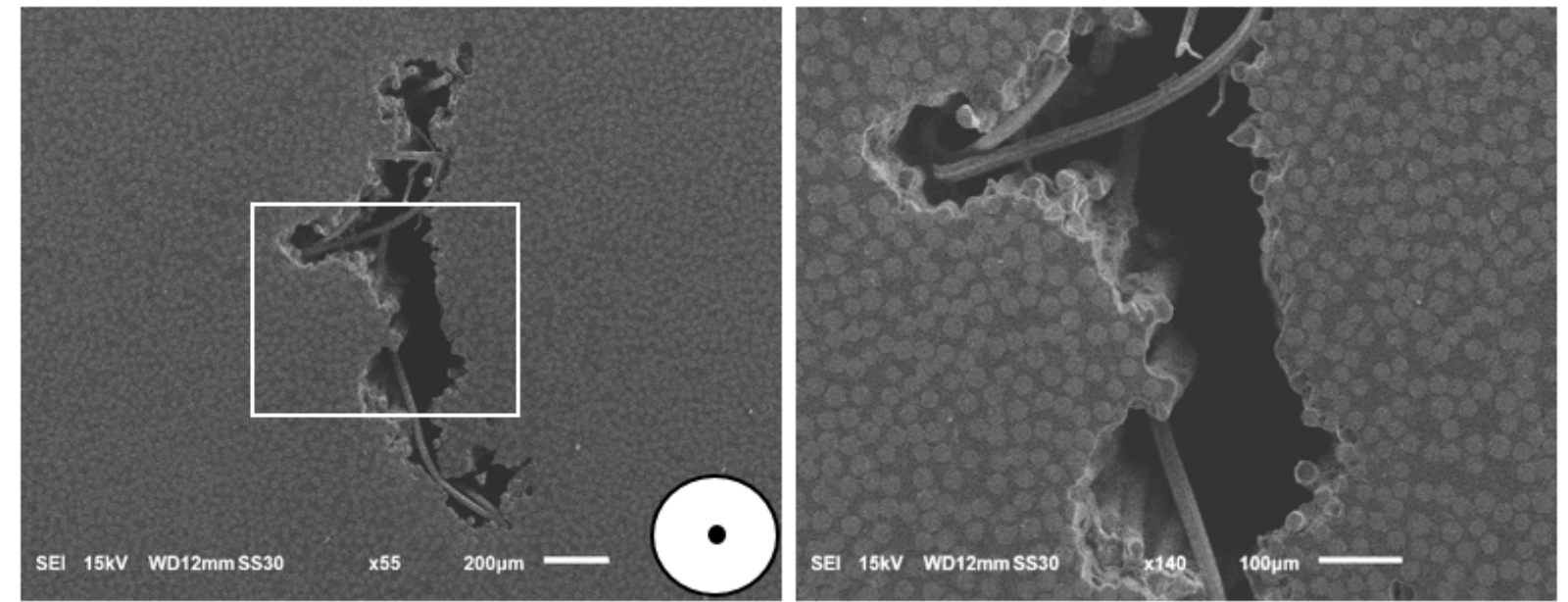
124 GFRP-Bdemonstrated a continuous defect along the edge as shown at different magnification levels in
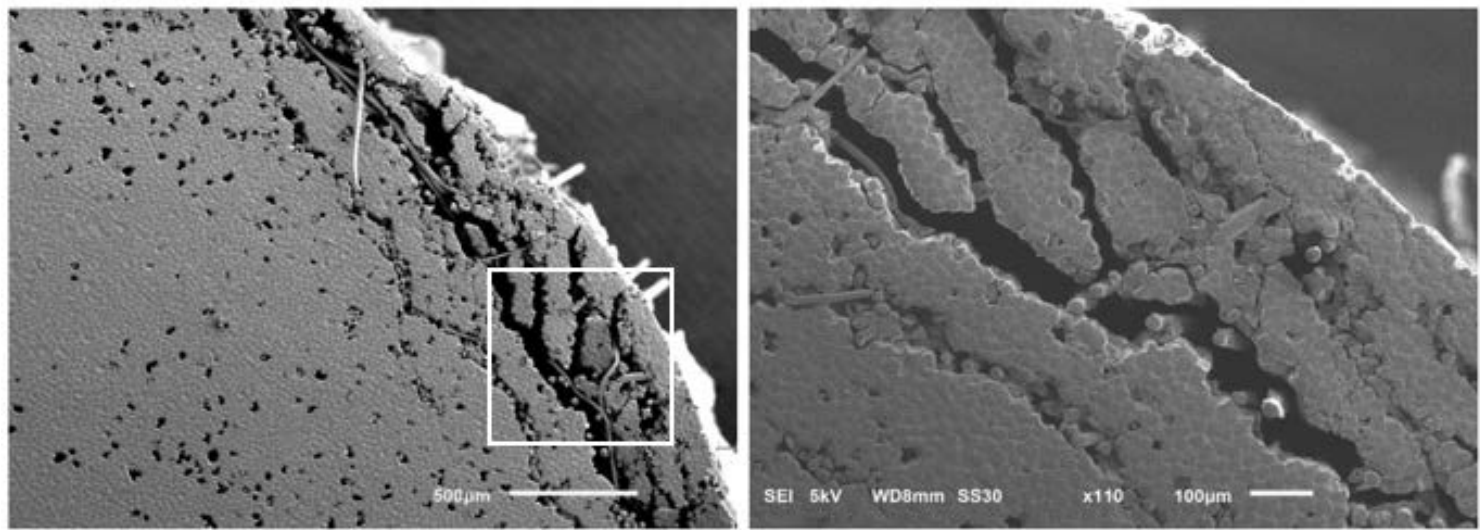

Figure 5:A continues defect at the edge ofGFRP-B at magnification levels of 40x (left) and 110x (right) 

of chemical and environmental attacksinitiatesat the boundaries.
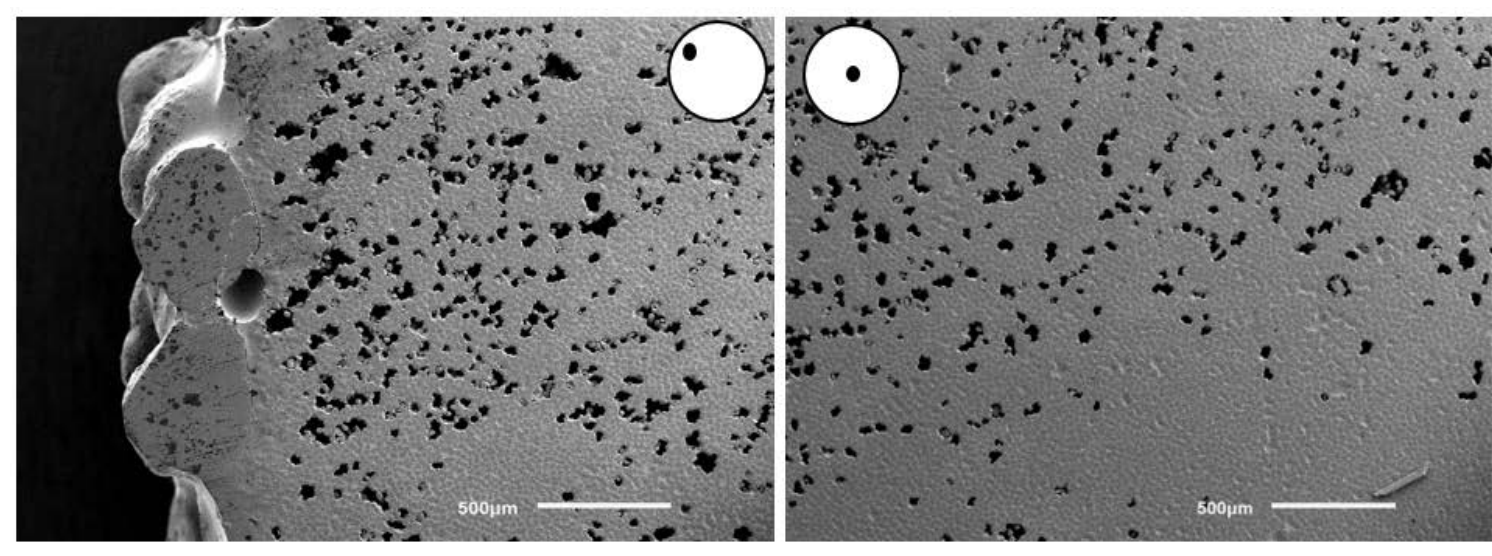

Figure 6:Distributed voids in the cross-section of GFRP-B: close to the edge (left), close to the center (right)

GFRP-C presented both connected defects and disconnected voids in the cross-section including the central portion and edges while no defect was observed at the surface of the bar (Figure 7-9). The continuous defect pattern across the entire section may be problematic for durability applications. This isespecially true for the defects close to the edge, sincedeterioration of the reinforcement due to diffusion
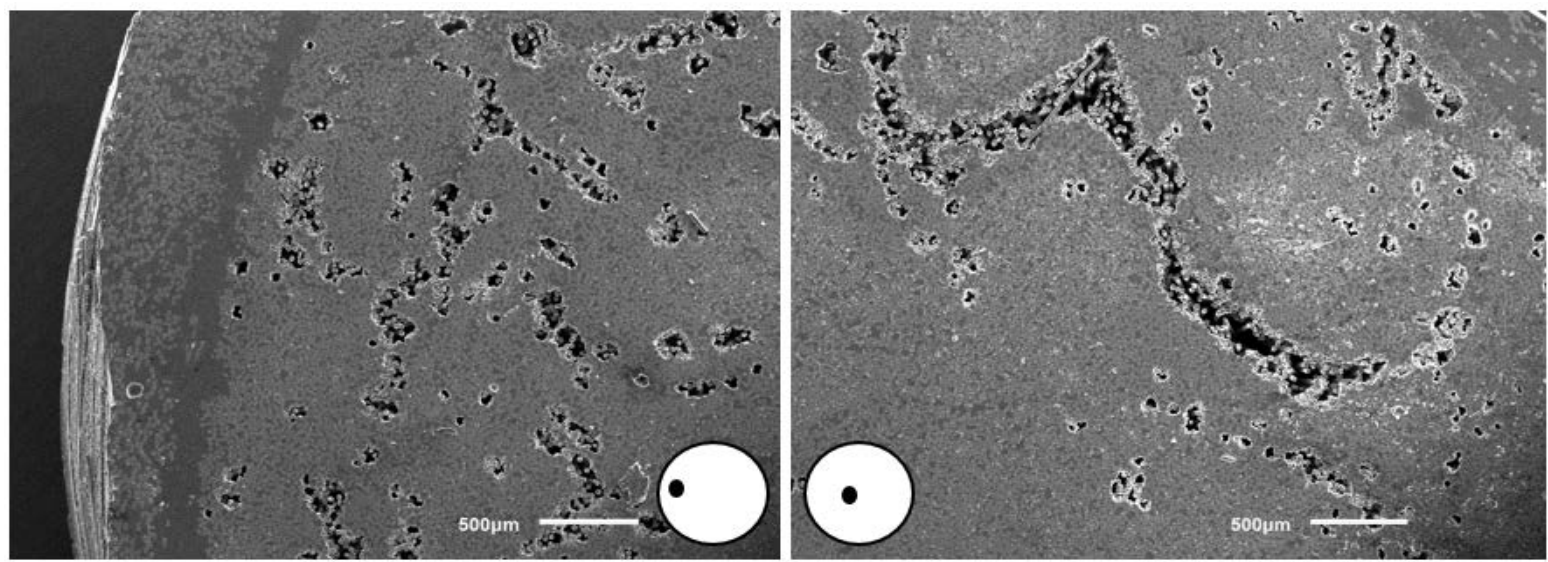

:Figure 7: Continuous defects at the edge (left) and at the center (right) of GFRP-C 

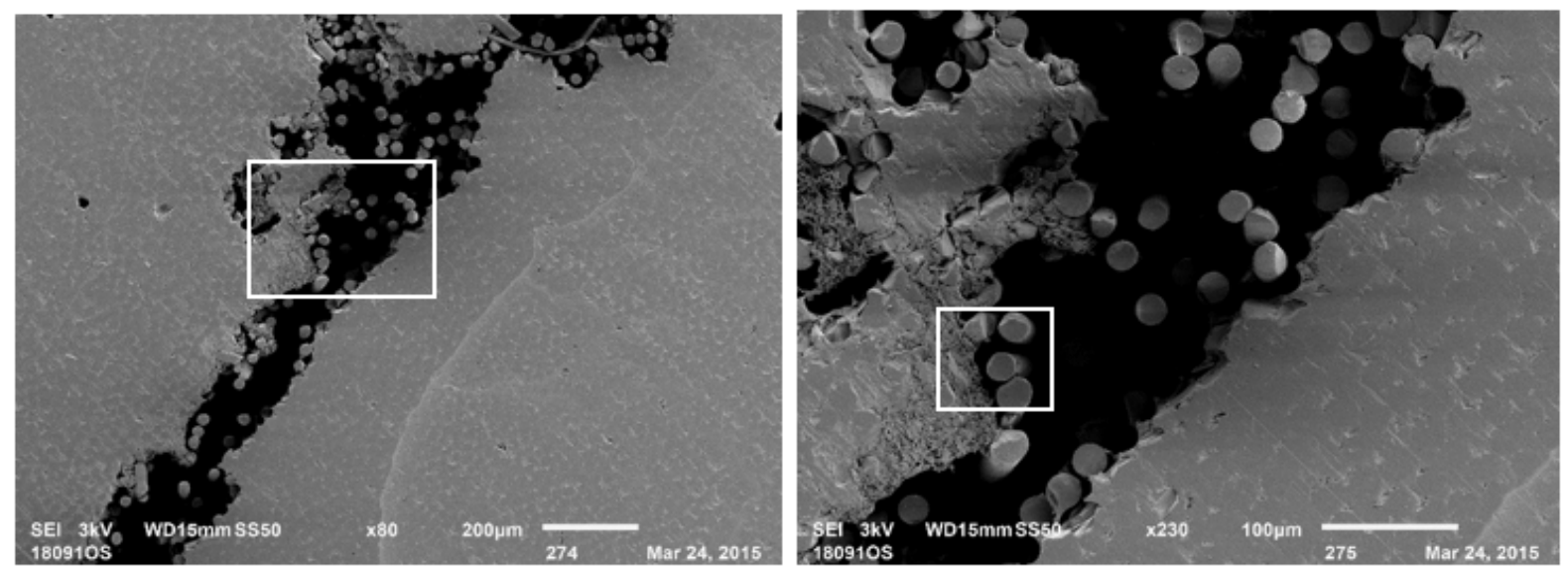

Figure 8:Detailed view of a defect close to the edgeof GFRP-C at magnification levels of 80x (left) and 230x (right)

145

146

147

148

149 GFRP-D demonstrated disconnected void patterns in the cross-section including both at the central

150 portion and edges (Figure 10). The number of voids reduced in the center compared to the edges. Figure

15111 provides higher magnification images of the voids and the no void area.

Figure 9:High magnification imageof a void (left) and area with no void (right) of GFRP-C
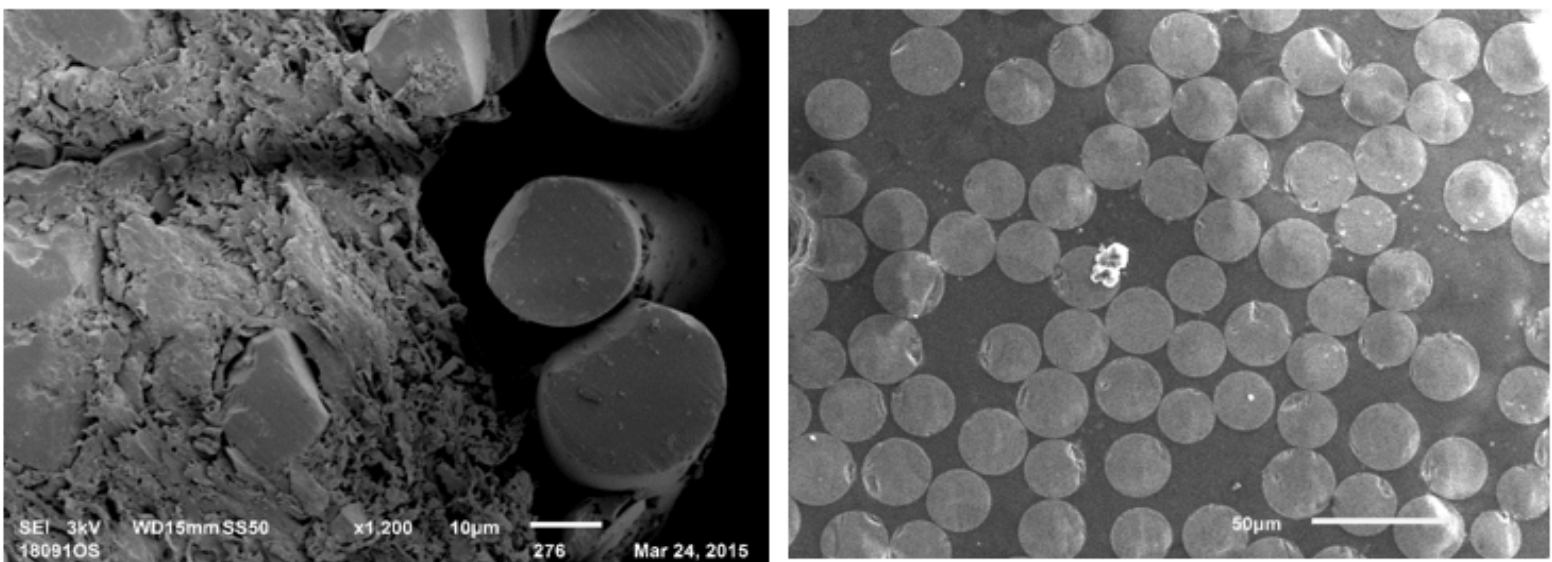

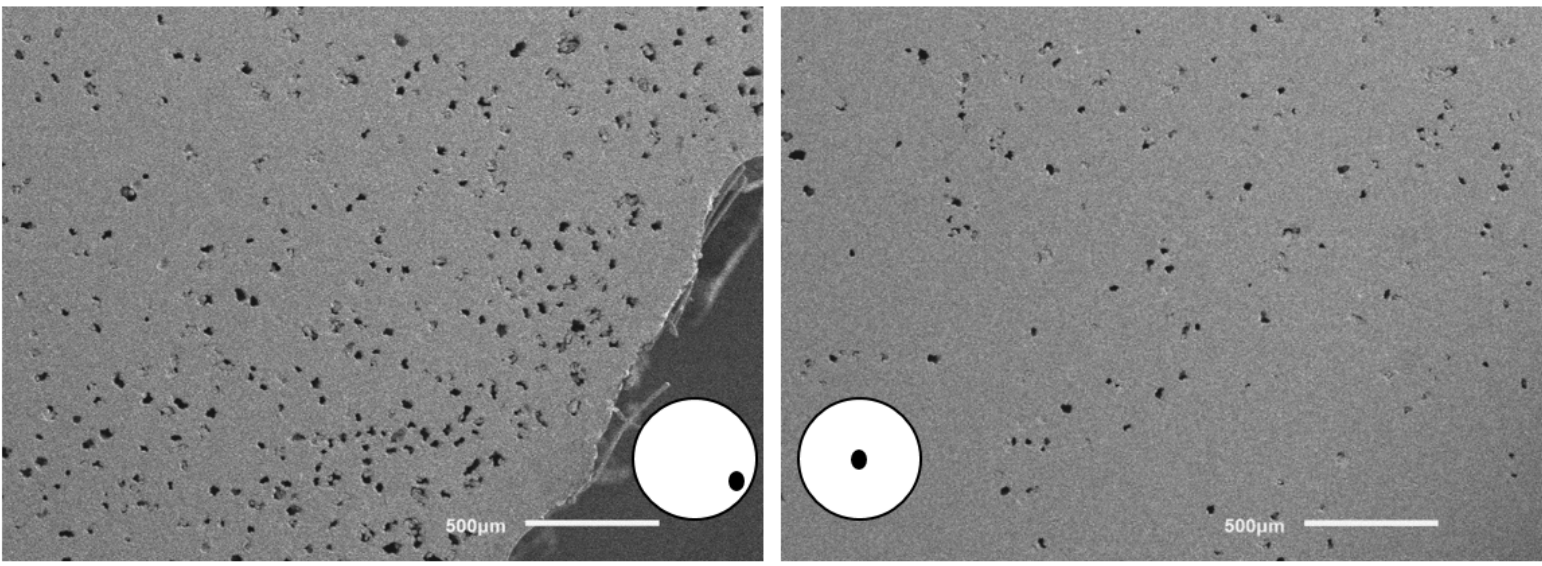

Figure 10:Disconnected void patterns at the edge (left) and center (right) of GFRP-D
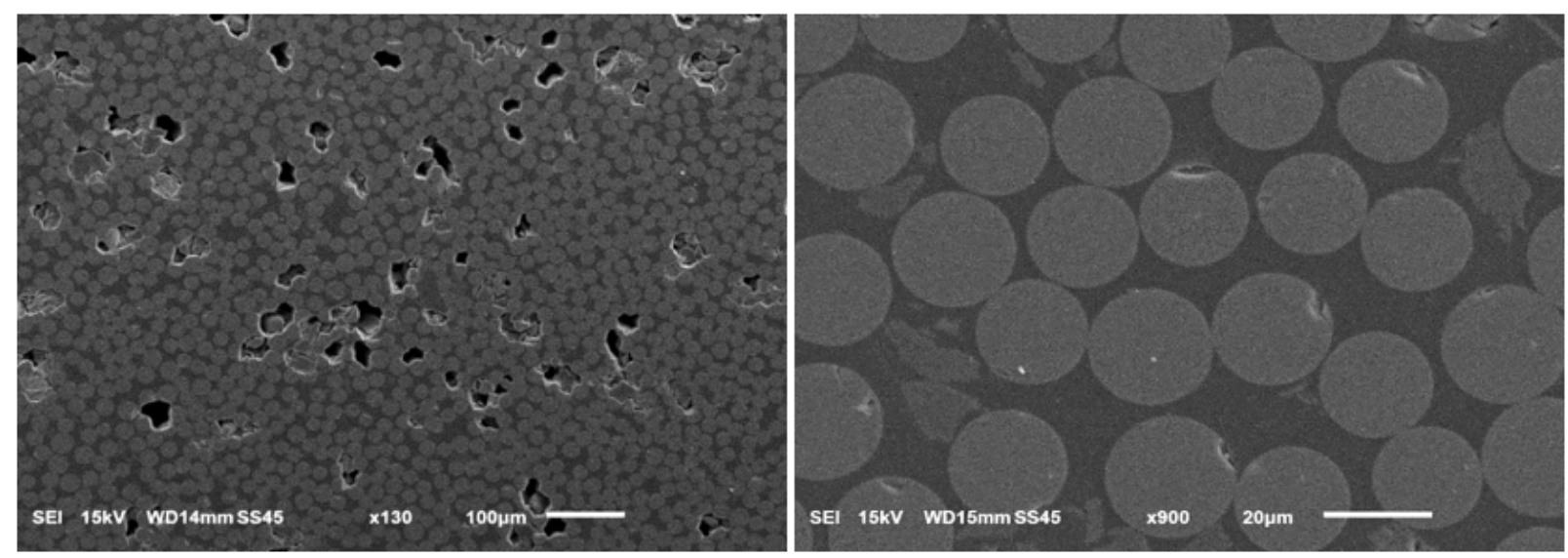

Figure 11: Higher magnification image of the areas with voids (left) and area with no void (right) of GFRP-D

Finally, Figure 12 provides a panorama image of the entire section for all the GFRP bars. It serves for

160 a proper comparison purpose and demonstrates that each bar had a unique microstructural pattern. The

161 observed defects in all GFRP bars were continuous along the length of the bar providing an evidence that

162 the defects are most likely related to the pultrusion and curing process. The defects can be reduced if not

163 entirely avoided by implementing quality control and using proper manufacturing parameters such as

164 pultrusion speed, dye temperature and curing time. It is also possible that some of the secondary

165 constituents such as fillers and additives may improve the quality of the final product. 

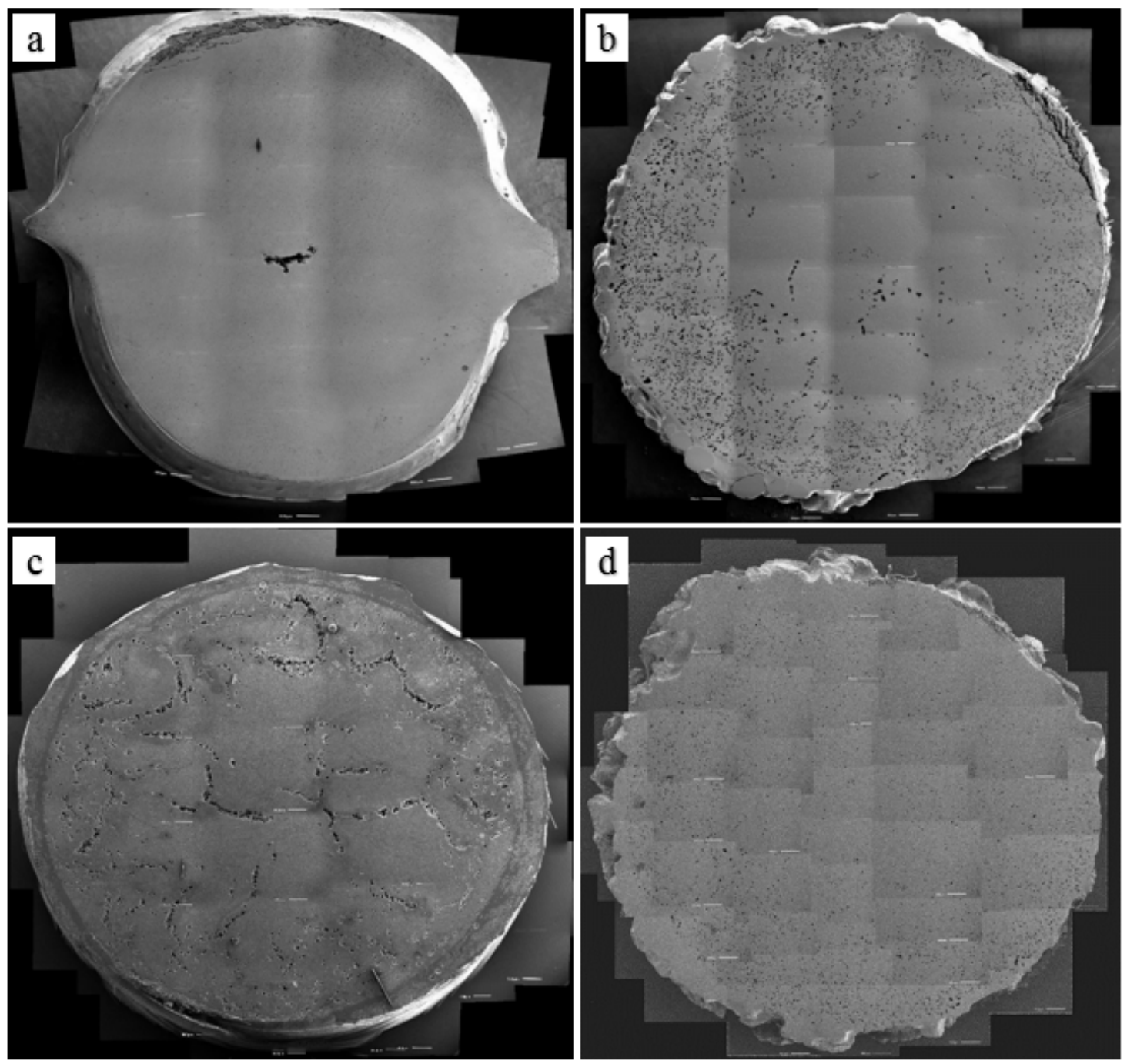

Figure 12:Panorama images ofGFRP-A (a), GFRP-B (b), GFRP-C (c), and GFRP-D (d)

\section{Alkaline Conditioning}

171 GFRP-A and GFRP-C were selected among the four types and exposed to an alkaline solution with the

$172 \mathrm{pH}$ of 12.5-13for a duration of 1000 hours. The alkaline solution was prepared following the ACI-440.3R

173 by mixing 118.5 gr of $\mathrm{Ca}(\mathrm{OH})_{2}, 0.9$ gr of $\mathrm{NaOH}$ and $4.2 \mathrm{gr}$ of $\mathrm{KOH}$ in one liter of distilled water[7]. A

174 temperature of $60{ }^{\circ} \mathrm{C}$ was chosen to accelerate the exposure effect[4]. Five samples for each bar with the

175 length of $0.5 \mathrm{~m}$ were placed in the environmental chamber. The GFRP ends were sealed with epoxy to

176 reduce the effect of moisture absorption through the ends. Next, the horizontal shear strength was 
178 mechanical properties at fiber-resin interface and is a proper indication of durability and quality control.

179 Five conditioned coupons with the length of $50.8 \mathrm{~mm}$ were tested for each bar type. The same number of 180 coupons was taken from pristine bars and tested as benchmark. GFRP durability in alkaline environment 181 was not the main focus of the study and thus a limited number of coupons was tested. The conditioning of 182 the bars and the following horizontal shear tests were performed to simply provide evidence on the 183 possible effect of microstructural pattern on GFRP durability.

184 Test span was set as three times of bar diameter following the standard[8].The load was applied in 185 displacement control mode at a rate of $1.27 \mathrm{~mm} / \mathrm{min}$. The test Fixture is shown in Figure 13.

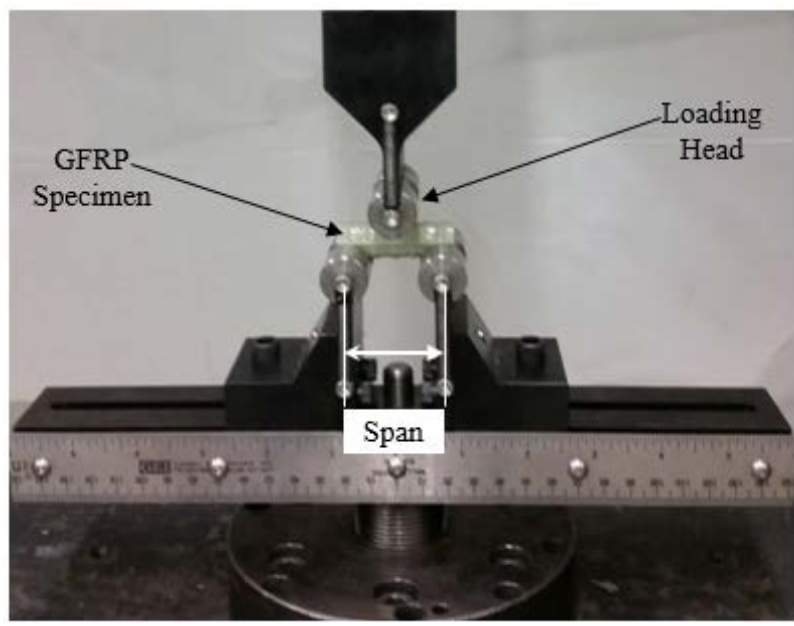

Figure 13:Horizontal shear test fixture

Table 2 reports the average results, where $S_{p}$ refers to the horizontal shear strength of the pristine, and

$191 S_{e}$ refers to horizontal shear strength of the conditionedsample. The same notation is used for the failure 192 load $(P)$. Based on the results, after 1000 hours of exposure to alkaline solution at $60{ }^{\circ} \mathrm{C}$, the horizontal 193 shear strength of GFRP-A decreased only by 1\% compared to the pristine values while GFRP-C 194 demonstrated 15\% reduction in horizontal shear strength. 
Table 2:Result of the horizontal shear tests on pristine and conditioned GFRP samples

\begin{tabular}{|c|c|c|c|c|c|c|c|c|c|}
\hline \multirow[b]{2}{*}{ Type } & \multicolumn{3}{|c|}{$P_{p}$} & \multicolumn{3}{|c|}{$P_{e}$} & \multirow[b]{2}{*}{$\begin{array}{c}S_{p} \\
(\mathrm{MPa})\end{array}$} & \multirow[b]{2}{*}{$\begin{array}{c}S_{e} \\
(\mathrm{MPa})\end{array}$} & \multirow[b]{2}{*}{$\begin{array}{l}\text { Ratio } \\
\left(S_{e} / S_{p}\right)\end{array}$} \\
\hline & $\begin{array}{c}\text { No. of } \\
\text { Samples } \\
\end{array}$ & $\begin{array}{c}\text { Average } \\
(\mathrm{kN})\end{array}$ & $\begin{array}{l}\mathrm{CoV} \\
(\%)\end{array}$ & $\begin{array}{c}\text { No. of } \\
\text { Samples } \\
\end{array}$ & $\begin{array}{c}\text { Average } \\
(\mathrm{kN})\end{array}$ & $\begin{array}{l}\text { Cov } \\
(\%) \\
\end{array}$ & & & \\
\hline GFRP-A & 5 & 12.19 & 12.2 & 5 & 12.07 & 4.0 & 64.16 & 63.55 & 0.99 \\
\hline GFRP-C & 5 & 10.45 & 9.2 & 5 & 8.91 & 3.5 & 54.93 & 46.90 & 0.85 \\
\hline
\end{tabular}

Note: 1 kN= 0.2248 kip; 1 psi=0.0069 MPa

The results obtained from the horizontal shear test was consistent with the expectations from the SEM imaging. The entire cross-section of GFRP-C was covered with continuous defects and disconnectedvoids and they were expected to dramatically affect its durability. GFRP-A was characterized with no voids and defect patterns and demonstrated a proper resistance to alkaline conditioning. Additional evidencewas

204 provided by performing SEM imaging on conditioned samples to investigate the change in microstructure 205 at the vicinity of the existing defect patterns. Figure 14 shows the conditioned and intact regions and the 206 alkaline surface penetration in GFRP-A. Themicrostructure of GFRP-A did not include any defect or void 207 pattern, as a result, no localized damage was observed as the alkaline frontpenetrated from the edge 208 toward the core of the cross-section.

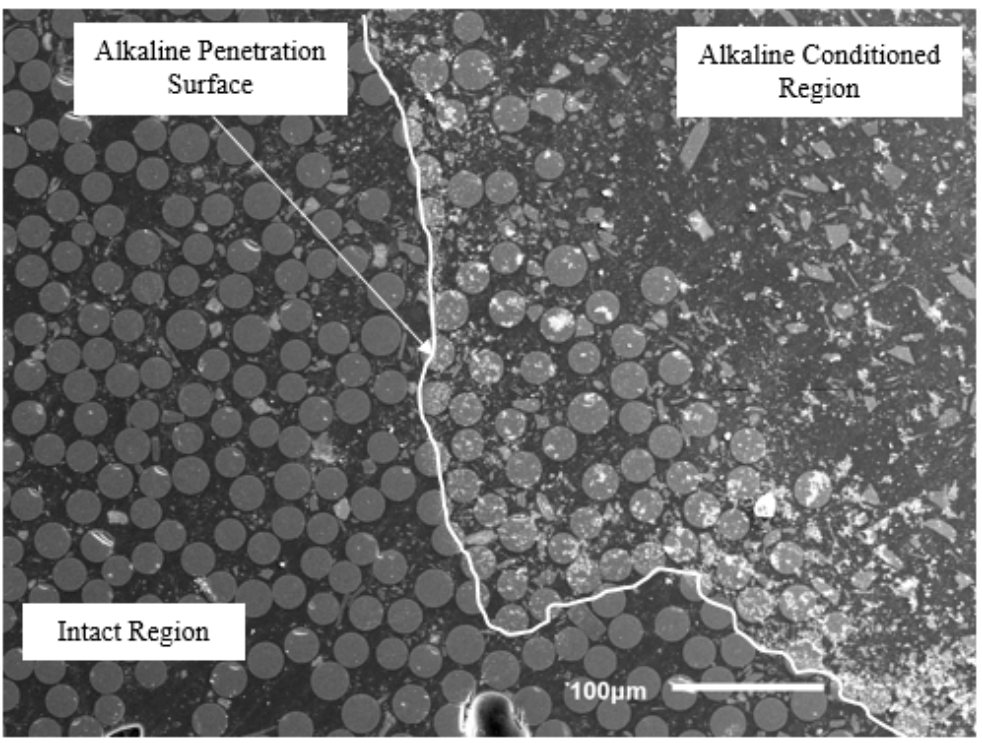

Figure 14: Conditioned and intact regions in GFRP-A 
212 Conversely, SEM images of GFRP-Ccross-section presented extensive damage in the vicinity of the

213 existing defects. Figure 15 shows a region of the alkaline conditioned GFRP-Cpresenting the damage in

214 the resin and glass fibers. Additionally, Figure 16shows excessive fiber degradationin the vicinity of an

215 existing defect. The damaged area was not clearly separated by a front line from the intact region

216 confirming one more time the higher vulnerability of this bar type.

217

218

219

220
221

223

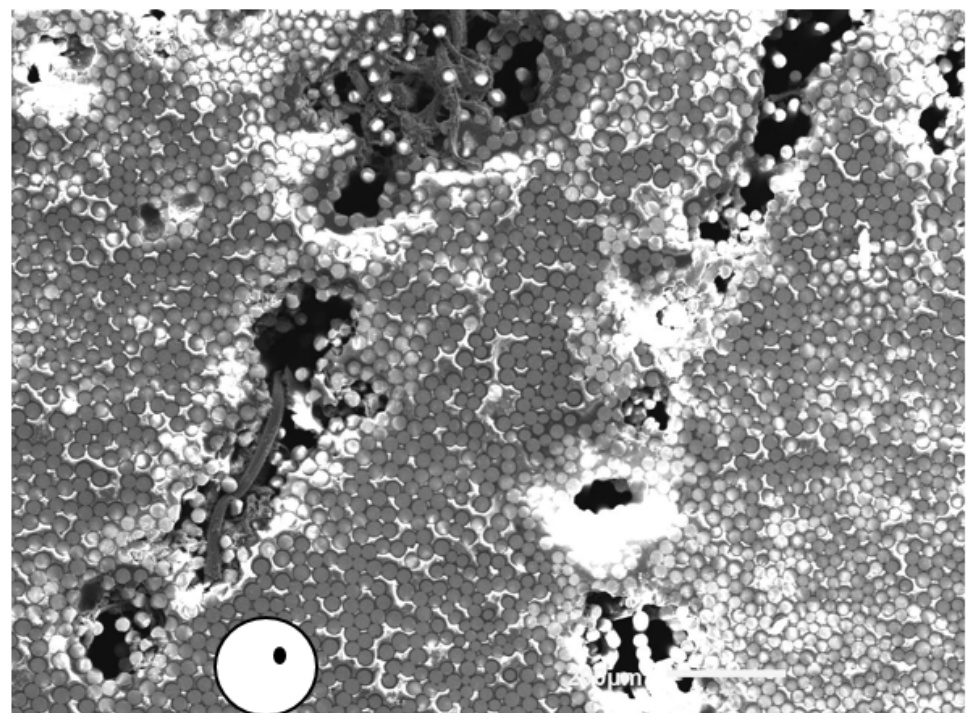

Figure 15: A conditioned region of GFRP-C presenting an extensive damage in resin and glass fibers

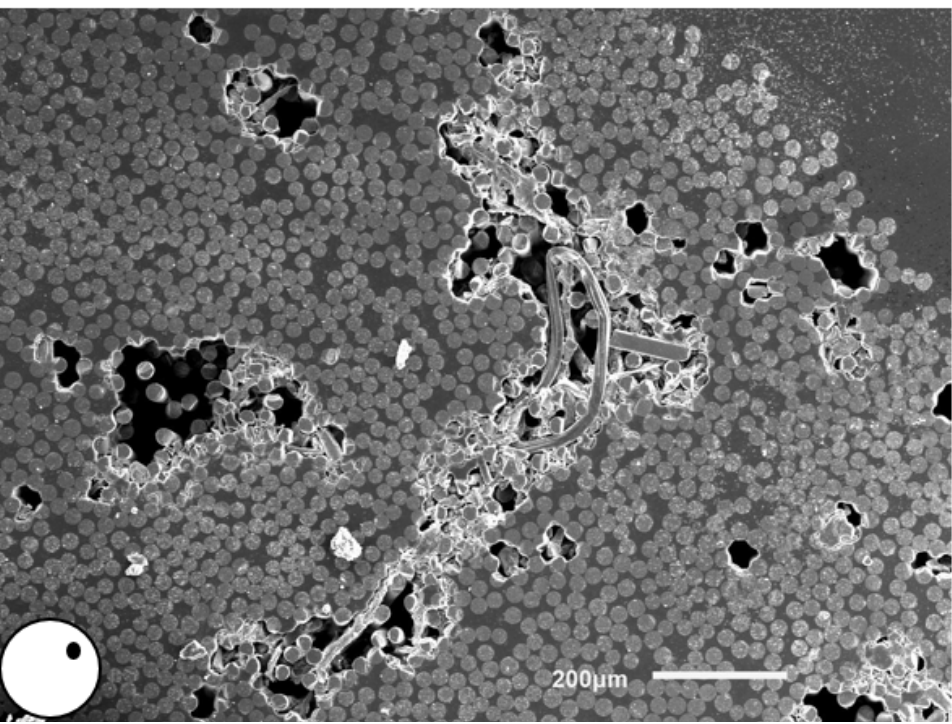

Figure 16: A conditioned region of GFRP-C presenting an extensive damage in the fibers in the vicinity of existing defects 


\section{Conclusion}

225 SEM imaging was performed at different magnification levels on four different commercially available

226 GFRP barsproduced by pultrusion. Only one diameter size was investigated. Each bar presented unique

227 microstructural patterns due to different manufacturing parameters and possibly constituent materials,

228 including fillers and additives, used by the manufacturer. The effects of these patterns on GFRP durability

229 was investigated by accelerated conditioning in alkaline solution of two of the bars. Horizontal shear tests

230 were performed as an indicator of durability. SEM imaging was conducted on the conditioned samples to

231 provide additional data. According to the results from the SEM imaging and mechanical testing, the

232 following observations are made:

- Each GFRP bar demonstrated a unique signature of existing defect and void patterns characterized by a combination of disconnected voids and continuous defects at different locations in the cross- sectionmost likely due to different manufacturing parameters such as pulling speed, dye temperature and curing time and constituent materials.

- GFRP-A presented the lowest existing void/defect compared to other GFRP bars. There was a single void in the center of the bar and a macro defect at the edge. GFRP-B demonstrated both disconnected voids mostly at the vicinity of the edges as well as the defects along the edges of the bar. GFRP-C presented the most voids and defects in the cross-section compared to other GFRP bars. It mostly included continuous defectsover the entire area. GFRP-D presented disconnected voids all over the cross-section while there were fewer voids at the center of the bar compared to the edges.

- All the observed defects were continuous along the length of the bar confirming that the defects are the results of manufacturing. These defects can possibly be reduced by implementing better quality control practices and using proper manufacturing parameters. 
- After 1000 hours of exposure to accelerated conditioning in a high $\mathrm{pH}$ alkaline environment at 60 ${ }^{\circ} \mathrm{C}$, GFRP-A did not experience any change in itshorizontal shear strength (less than one 1\%) while GFRP-C demonstrated 15\% loss of this mechanical property.

- Different penetration of alkaline front was observed in GFRP bars with different microstructural patterns.Additionally, extensive deterioration was noticed at the vicinity of existing defects and voids. bars.

The results of this study can be used as a benchmark for microstructure analysis of commercially available pristine GFRP bars and serve as a base for monitoring possible changes after conditioning or 257 field use.

258

\section{Acknowledgements}

260 The authors gratefully acknowledge the National Science Foundation (NSF) and its industrial members

261 for the support provided to the Industry/University Center for Integration of Composites into

262 Infrastructure (CICI) at the University of Miami under grant NSF IIP-1439543. 
1. Nanni A, De Luca A, Jawaheri Zadeh H. Reinforced Concrete with FRP Bars: Mechanics and Design, CRC Press 2014.

2. Mukherji S, Arwikar S.J. Performance of Glass Fiber-Reinforced Polymer Reinforcing Bars in Tropical Environments-Part II: Microstructural Test.ACI Structural J. 2005;vol. 102, pp. 816-822.

3. Mufti A, Banthia N, Benmokrane B, Boulfiza M, Newhook J.Durability of GFRP Composite Rods.Concrete International 2007;vol. 29, pp. 37-42.

4. Micelli F, Nanni A. Durability of FRP Rods for Concrete Structures.J. of Construction and Building Materials 2004;vol. 18, pp. 491-503.

5. Claure G, Basalo F, Nanni A. Cross-Sectional Area of GFRP Bars for Concrete Reinforcement.ASTM International2015 (Unsder Review).

6. ASTM D792. Standard Test Methods for Density and Specific Gravity (Relative Density) of Plastics by Displacement, Density, Relative Density, Specific Gravity.ASTM International2013; West Conshohocken, PA.

7. ACI 440.3R. Guide Test Methods for Fiber-Reinforced Polymers (FRPs) for Reinforcing or Strengthening Concrete Structures.American Concrete Institute2012; Farmington Hills, MI.

8. ASTM D4475. Apparent Horizontal Shear Strength of Pultruded Reinforced Plastic Rods by the Short-Beam Method.ASTM International2008; Farmington Hills, MI. 


\section{Figure Captions}

277 Figure 1: Representative prepared samples (from left: GFRP-A, B, C, and D)................................... 5

278 Figure 2: A defect at the edge of GFRP-A at magnification levels of 80x (left) and 150x (right) .............6

279 Figure 3: Detailed view of a void in the center of GFRP-A at magnification levels of 55x (left) and 140x

280

(right)

281 Figure 4: Area with no void of GFRP-A at magnification levels of 350x (left) and 1200x (right) 7

282 Figure 5: A continues defect at the edge of GFRP-B at magnification levels of 40x (left) and 110x (right)7

283 Figure 6: Distributed voids in the cross-section of GFRP-B: close to the edge (left), close to the center

284 (right) 8

285 Figure 7: Continuous defects at the edge (left) and at the center (right) of GFRP-C ...... 8

286 Figure 8: Detailed view of a defect close to the edge of GFRP-C at magnification levels of 80x (left) and

287 230x (right) 9

288 Figure 9: High magnification image of a void (left) and area with no void (right) of GFRP-C 9

289 Figure 10: Disconnected void patterns at the edge (left) and center (right) of GFRP-D 10

290 Figure 11: Higher magnification image of the areas with voids (left) and area with no void (right) of

292 Figure 12: Panorama images of GFRP-A (a), GFRP-B (b), GFRP-C (c), and GFRP-D (d) 11

Figure 13: Horizontal shear test fixture 12

Figure 14: Conditioned and intact regions in GFRP-A.

Figure 15: A conditioned region of GFRP-C presenting an extensive damage in resin and glass fibers ... 14 


\section{11. Table Captions}

301 Table 1: GFRP nominal and measured cross-sectional areas ….................................................... 4

302 Table 2: Result of the horizontal shear tests on pristine and conditioned GFRP samples ........................ 13

303 